\title{
Estrutura organizacional do serviço de enfermagem: reflexões sobre a influência do poder e da cultura organizacional
}

\author{
ORGANIZATIONAL STRUCTURE OF NURSING SERVICES: REFLECTIONS ON THE \\ INFLUENCE OF THE ORGANIZATIONAL POWER AND CULTURE \\ ESTRUCTURA ORGANIZACIONAL DEL SERVICIO DE ENFERMERÍA: REFLEXIONES \\ SOBRE LA INFLUENCIA DEL PODER Y DE LA CULTURA ORGANIZACIONAL
}

\section{Marli de Carvalho Jericó ${ }^{1}$, Aida Maris Peres ${ }^{2}$, Paulina Kurcgant ${ }^{3}$}

\section{RESUMO}

Este estudo discute a cultura e o poder influenciando a estrutura organizacional do serviço de enfermagem em um hospital de ensino. A partir da necessidade de padronizar os procedimentos de enfermagem por parte da administração geral do hospital, foi desenhada a estrutura organizacional (organograma) do Serviço de Enfermagem. Por causa desta situação, veio à tona o interesse dos enfermeiros gestores em ampliar o espaço de poder, fortalecendo a Enfermagem no ambiente intra-institucional.

\section{DESCRITORES}

Enfermagem.

Serviços de enfermagem.

Poder (Psicologia).

Cultura organizacional.

Negociação.

Conflito (Psicologia).

\begin{abstract}
This study addresses the culture and power influencing the organizational structure of the nursing services at a teaching hospital. The Nursing Service organizational structure (organization chart) was outlined due to the need of the general management of the hospital to standardize the nursing procedures. Due to this situation, the nursing managers' interest has arisen to widen the power setting, strengthening nursing in an intra-institutional environment.
\end{abstract}

\section{KEY WORDS \\ Nursing. \\ Nursing services. \\ Power (Psychology). \\ Organizational culture. \\ Negotiation. \\ Conflict (Psychology).}

\section{RESUMEN}

Este artículo analiza cómo la cultura y el poder influyen en la estructura organizacional del servicio de enfermería en un hospital-escuela. Basados en la necesidad de protocolizar los procedimientos de enfermería, por parte de la administración general del hospital, se diseñó la estructura organizacional (organigrama) del Servicio de Enfermería. De esta forma fue evidenciado el interés de los enfermeros-jefes por ampliar el poder, fortaleciendo el sector de enfermería dentro del ámbito institucional.

\author{
DESCRIPTORES \\ Enfermería. \\ Servicios de enfermería. \\ Poder (Psicología). \\ Cultura organizacional. \\ Negociación. \\ Conflicto (Psicología).
}

1 Enfermeira. Doutoranda da Escola de Enfermagem, Universidade de São Paulo (EEUSP). Professora do Curso de Graduação em Enfermagem da Faculdade de Medicina de São José do Rio Preto. São José do Rio Preto, SP, Brasil. marli.jerico@famerp.br ${ }^{2}$ Enfermeira. Doutoranda da Escola de Enfermagem, Universidade de São Paulo (EEUSP). Professora do Curso de Graduação em Enfermagem da Universidade Federal do Paraná. Curitiba, PR, Brasil. amaris@ufpr.br ${ }^{3}$ Enfermeira. Professora Titular do Departamento de Orientação Profissional da Escola de Enfermagem, Universidade de São Paulo (EEUSP). São Paulo, SP, Brasil. 


\section{INTRODUÇÃO}

As organizações de saúde são moldadas pelas crenças e valores de quem as constituíram (fundadores ou dirigentes) que, coletivamente, num determinado contexto, criam e expressam suas opiniões, estabelecem normas, desenhos que delineiam suas estruturas, manuais de técnicas e procedimentos. Ainda, utilizam recursos e geram uma produção - a assistência, atingindo os objetivos organizacionais. Assim, a cultura organizacional resulta das crenças e valores que orientam as decisões do gestor em todos os níveis da estrutura organizacional direcionando qual o caminho a ser seguido diante de várias alternativas de ação.

O reconhecimento do ambiente organizacional permite a detecção e o aprofundamento da análise de fatores contingenciais que interferem direta ou indiretamente no planejamento, execução, controle e avaliação das atividades de enfermagem. A identificação das estruturas formal e informal, presentes em todas as organizações facilitam a participação no fluxo comunicacional, no planejamento e no desenvolvimento de ações mais flexíveis que permitem a satisfação no processo de trabalho.

A estrutura formal acontece baseada na divisão de trabalho racional, especializando setores, órgãos e pessoas em determinadas atividades ${ }^{(1)}$. A forma de compor o grupo costuma ser planejada e exposta numa estrutura com papéis, hierarquia e classificação de cargos definidos ${ }^{(2)}$.

Já a estrutura informal tem natureza social, não delimitada pela organização; carece de planejamento e mantém-se encoberta ${ }^{(2)}$. Sua aparição é espontânea e natural, principalmente entre os ocupantes de cargos formais que se aproveitam dos diversos relacionamentos humanos advindos de seu status(1). Esses grupos informais não são identificados no organograma e não devem ser desconsiderados. Em instituições que estimulam esta estrutura, a participação dos funcionários é mais abrangente, assim como, o surgimento de novas lideranças que acabam constituindo um grupo forte de trabalho.

Este estudo justifica-se pela necessidade de trazer à tona a discussão sobre as influências da cultura e das relações de poder na organização dos serviços de enfermagem por meio de um relato de experiência. Através de reflexões advindas desta vivência, pretende-se contribuir com os enfermeiros no enfrentamento dos desafios constantes de construir uma estrutura formal que garanta relações de poder mais horizontais no ambiente de trabalho.

Portanto, o propósito deste estudo é analisar a estrutura formal do Serviço de Enfermagem de uma organização de cuidados de saúde.

\section{REVISÃO DA LITERATURA}

Historicamente, as variáveis intervenientes na estrutura de uma empresa não obedecem a princípios rígidos de Administração, mas a fatores presentes em sua cultura, tamanho e sistema técnico, dinâmica de demanda, complexidade tecnológica empregada como também ao poder, fatores estes que influenciam nas decisões. A interdependência e o equilíbrio entre a estrutura organizacional e o seu contexto devem atingir adequadamente os objetivos da organização(3).

Analisando o ambiente da instituição hospitalar em questão, tornou-se necessário aprofundar o estudo sobre a cultura e o poder organizacional e suas relações com a Enfermagem. A estrutura formal e informal da organização é apresentada, levando-se em conta as influências que sofre da cultura e do poder.

\section{Cultura Organizacional}

Alguns autores ${ }^{(1-2,4)}$ atentam para a diferenciação entre os conceitos de clima e cultura organizacional. Porém, nessa tentativa de diferenciação surgem contradições.

A cultura

organizacional resulta Um desses conceitos afirma que o clima organizacional resulta do envolvimento de diferentes fatores, percebidos de diferentes maneiras, por diferentes indivíduos. Como exemplo, o autor cita os componentes relacionados a aspectos formais e informais da organização. Todo povo tem a sua cultura própria. E também cada organização tem a sua cultura ${ }^{(1)}$. Assim, é considerado o caráter de diferentes culturas organizacionais que pode ser renovado freqüentemente, mantendo a personalidade da organização, ou permanecer com padrões ultrapassados.

Numa outra visão(4), assim como a cultura, o clima organizacional é constituído a partir de seu ideário ou de preceitos explícitos e implícitos, de seu know-how ou tecnologia e pelo seu caráter, entendido como sentimentos e reações das pessoas. Aqui, o clima organizacional é percebido como menos duradouro que a cultura, que se concretiza com o tempo através dos seus hábitos, costumes e conhecimento. Clima organizacional pode ser entendido sob a forma de como a organização é percebida pelos funcionários, podendo ser diferente da sua cultura ${ }^{(2)}$.

Dois especialistas ${ }^{(5)}$, considerados como os responsáveis pela efetivação da Teoria Geral de Sistemas nas organizações, apontam que a cultura organizacional reflete as normas e valores do sistema formal como uma reinterpretação do sistema informal. Seguindo essa linha de raciocínio, alegam ainda que, assim como a sociedade, as organizações possuem uma herança cultural transmitida aos novos membros. 
Na área da saúde é marcante a influência da cultura na organização hospitalar. Em estudo realizado com enfermeiros de um hospital de ensino(6), a cultura da enfermagem é refletida ao serem identificados seus três principais fatores motivacionais: $70 \%$ dos enfermeiros consideram a importância do fazer, categorizada como necessidade de realização; 7\%, a importância em influenciar pessoas, categorizada como necessidade de poder, e outros $7 \%$ valorizam a comunhão com o grupo, considerada necessidade de afiliação. A qualidade do trabalho do enfermeiro, como fator dependente do desempenho de um grupo de pessoas foi característica marcante da cultura da enfermagem no local estudado.

\section{Relações de poder}

São muitas as definições para o poder:

poder é o potencial que as pessoas têm para exercer influência sobre o comportamento de outras. É a capacidade de modificar, canalizar e persuadir outra pessoa a fazer algo que ela não faria necessariamente, se não fosse influenciada nesse sentido(7).

Contrapondo-se a essa definição existe uma corrente filosófica que defende a não existência do poder, porque realmente o que existem são práticas de relação de poder, como algo que se exerce, que se efetua, que está em ação, numa disputa em que se ganha ou se perde ${ }^{(8)}$.

O poder capacita o indivíduo a atingir metas e autoridade e é sinônimo de um direito legitimado de comandar ${ }^{(2)}$. A distinção entre poder e autoridade pode ser percebida ao ser conceituado poder como o potencial para exercer influência, sem que essa influência obrigatoriamente seja exercida. Já a identificação de autoridade é mais controvertida porque representa o poder legal, institucionalizado. A autoridade é sempre imbuída de poder, mas o poder nem sempre está ligado à autoridade institucionalizada ${ }^{(1)}$.

O poder tem raízes na prática cotidiana da organização. A ideologia e os dispositivos operacionais como as entrevistas, as mediações e as avaliações a que estão sujeitos os funcionários e que fazem parte dos procedimentos da organização, estão ligados, intimamente, à política de recursos humanos. Sob as vantagens concedidas pela organização, a mediação utiliza, como meio de subordinação, a abstração enquanto lógica abstrata em busca de dinheiro; a objetivação, cobrando a utilidade de cada um; a desterritorialização, separando as pessoas de suas raízes para receber melhor os códigos organizacionais; e a canalização da energia em força de trabalho, visando a carreira ${ }^{(9)}$. Assim, a prática do poder permite tornar visíveis as relações não reveladas nos organogramas e os discursos funcionalistas sobre a organização. A regulamentação é instrumento eficaz de poder, definindo padrões de comportamento organizacional, procurando dividir o trabalho garantido pela hierarquia ${ }^{(10)}$.

Na prática profissional, as funções administrativas exigidas pelos superiores hierárquicos aproximam os enfermei- ros dos níveis decisórios, numa situação de co-gestão, em que possuem maior responsabilidade no seu trabalho, mas sem participação efetiva na formulação de metas e objetivos institucionais ${ }^{(9)}$.

O gerenciamento do Serviço de Enfermagem não é tarefa simples, mas a grande dificuldade dos gerentes está na sua relação com a administração do hospital, que muitas vezes relega a segundo plano as necessidades do serviço de enfermagem ${ }^{(12)}$.

\section{MÉTODO}

Trata-se de um relato de experiência sobre a estrutura organizacional do Serviço de Enfermagem, cujo campo de estudo foi um hospital de ensino, de capacidade extra, localizado no interior do Estado de São Paulo, que tem diferentes cenários de especialidades médicas e assistenciais como também atividades de ensino e pesquisa. A organização é utilizada como campo de estágio para alunos de graduação em Enfermagem e Medicina.

O trabalho aqui descrito foi elaborado ao longo de seis meses do ano de 2001, com a realização de vinte e cinco reuniões com duração média de uma hora. Os participantes foram: a chefia do Serviço de Enfermagem e enfermeira assistente, dois enfermeiros do Centro de Educação Continuada (CEC) e três docentes da Disciplina de Administração do Curso de Enfermagem.

\section{Processo}

A partir da solicitação da padronização dos procedimentos de enfermagem por parte da Administração do hospital, o Centro de Educação Continuada (CEC) articulou uma reunião entre chefia do serviço de enfermagem, diretor executivo e superintendente do hospital, consultor externo atuante na instituição e um docente de administração do curso de enfermagem da instituição de ensino vinculada ao hospital.

No planejamento do programa houve a preocupação não apenas de atender às necessidades apontadas pela administração, mas sim de elaborar um programa de padronização de procedimentos de enfermagem baseado no modelo japonês ${ }^{(13)}$ de forma a agregar valor à prática. Concomitante ao grupo da padronização foi solicitado o treinamento dos enfermeiros gestores das unidades de internação, originando o segundo grupo, o da capacitação em gerenciamento da rotina do trabalho e posteriormente, um terceiro grupo denominado grupo de estruturação.

\section{Grupo 1 - Padronização de procedimentos de enfermagem}

O grupo foi constituído por enfermeiros assistenciais indicados pela chefia de enfermagem, um enfermeiro do CEC e docentes do Curso de Graduação em Enfermagem que tinham por objetivo orientar e acompanhar a realização da padronização dos procedimentos. 
O CEC ficou como o papel de centro de documentação dos Procedimentos Operacionais Padrão (POPs) traçando a arquitetura dos POPs quanto ao objetivo, criação (design), aplicação, divulgação, emissão, revisão, aprovação, extinção e histórico.

Logo no início dos encontros, o grupo de enfermeiros da instituição levantou questões sobre a informalidade da organização do serviço de enfermagem; a ambigüidade e duplicidade nas decisões; a falta de clareza dos limites de autoridade e, conseqüentemente do âmbito de decisão, pois o Serviço de Enfermagem não dispunha sequer de um regimento ou mesmo da descrição das atribuições dos cargos o que dificultava sobremaneira o direcionamento das ações do Serviço de Enfermagem. Em decorrência destas questões, tornou-se fundamental conhecer quem seria o executante da tarefa e quem realizaria a supervisão da padronização.

O questionamento do grupo ocorreu em função de que seu papel seria elaborar um manual de procedimentos que é a sistematização de todos os Procedimentos Operacionais Padrão (POPs) e em cada um deles responder: $O$ que faz? Quem faz? Quando faz? Onde faz? Como faz? Quais recursos? Contudo, a determinação de quem faz o quê, depende das atribuições designadas pelo Serviço de Enfermagem a cada função exercida na instituição em estudo. Dessa forma, emergiu a necessidade de um terceiro grupo de trabalho (grupo de estruturação) para elaboração da estrutura organizacional. $\mathrm{O}$ grupo construiu os POPs mais críticos e apresentou em reunião à chefia de enfermagem, diretoria executiva e superintendência no prazo estabelecido.

\section{Grupo 2 - Capacitação em gerenciamento da rotina do trabalho}

No programa, foram abordados os seguintes temas: gerenciamento participativo (4h), gerenciamento da rotina do trabalho do dia-a-dia com o levantamento dos principais problemas das unidades (12h).

A carga horária total foi de 16 horas, desenvolvida em encontros semanais, no período de setembro a outubro de 2001. Os participantes foram todos os enfermeiros (96) atuantes na instituição campo de estudo (turno manha, tarde e noite) coordenados por docentes da disciplina de Administração do Curso de Enfermagem e enfermeiros do CEC.

Como estratégias, foram utilizadas a exposição oral e dialogada, problematização e atividades práticas. A cada encontro resgatavam-se os aspectos mais relevantes abordados no encontro anterior e a aplicação no gerenciamento da unidade de cada enfermeiro. Os recursos audiovisuais utilizados com os enfermeiros foram retroprojetor, multimídia e flip-chart. Esse programa desenvolvido em parceria com o curso de graduação em Enfermagem deu-se em virtude das necessidades complementares existentes nos processos assistenciais e de ensino-aprendizagem. Conseqüente- mente, aproximou enfermeiros e docentes, fortalecendo o relacionamento entre as duas instituições.

\section{Grupo 3 - Estruturação}

Este grupo formado por enfermeiros do CEC, chefia de enfermagem e assistente, e docentes de administração do Curso de Enfermagem, tinha por objetivo elaborar a estrutura organizacional do Serviço de Enfermagem.

Antes do estudo, entendia-se que o Serviço de Enfermagem era composto dos seguintes cargos: chefia de enfermagem, enfermeiros supervisores, enfermeiros assistenciais, técnicos, auxiliares e atendentes de enfermagem; pois na chefia de enfermagem não tinha registros de sua organização, somente em nível de Departamento de Pessoal.

Trata-se de um hospital de capacidade extra, em que a chefia de enfermagem respondia por todas as atividades técnicas e administrativas desenvolvidas pela Enfermagem no hospital, ocasionando sobrecarga de trabalho. Dessa forma, o processo decisório centralizado na chefia de enfermagem obstruía o fluxo de comunicação ocasionando demora na tomada de decisão, distorções nas informações prejudicando a agilidade e a operacionalização do processo de trabalho.

Destaca-se que, na última década, o hospital tem crescido principalmente na área física, tecnológica e complexidade da assistência, constituindo um centro de referência para o município e para a região. Contudo, não houve, simultaneamente, investimento no que se refere ao dimensionamento quanti-qualitativo de recursos humanos de enfermagem. Assim, é possível que esta proposta atenda não somente à melhoria da assistência, bem como às necessidades gerenciais.

Corroborando este fato, estudo sobre saberes e poderes no hospital explica que os hospitais modernos têm crescido em nível físico e tecnológico, o que tem exigido modificações importantes na estrutura hierárquica e de poder vigentes $^{(14)}$. Não obstante ao avanço tecnológico, as organizações de saúde não têm acompanhado a evolução das organizações modernas, no que diz respeito às propostas de gestão ${ }^{(15)}$

Para o redesenho da estrutura organizacional os cargos foram renomeados, uma vez que as atribuições de cada nível haviam sido igualmente rediscutidas. Além disso, foram elaborados os perfis requeridos para ocupar cada cargo e função.

A proposta desenhada foi composta de: diretoria de enfermagem, gerentes de área, coordenadores da assistência, supervisores da assistência, técnicos e auxiliares de enfermagem, ou seja, acrescentou-se um nível hierárquico - gerentes de área. $O$ acréscimo deste nível tornouse necessário diante do crescimento vertiginoso da instituição, com oferecimento de novos serviços e, conseqüentemente, aumento da amplitude de ação da enfermagem. 0 
novo nível tinha foco gerencial para intensificar a comunicação colateral e, principalmente, descentralizar as atividades técnicas da chefia de enfermagem.

Esta clareza nos relacionamentos hierárquicos é essencial na gestão de pessoas e normalmente sofre influência da cultura e da política organizacional. Dessa forma, descentralizou-se o poder decisório e incrementou-se o fluxo de comunicação, dando maior agilidade ao processo de trabalho, com diminuição da sobrecarga para a chefia de enfermagem. A estrutura formal proposta contemplou o deslocamento das linhas de poder, antes fortemente centradas do nível operacional, para o nível estratégico, possibilitando o fortalecimento e visibilidade da Enfermagem.

As propostas dos três grupos (padronização, capacitação e estruturação) foram incorporadas em um único projeto e submetidas à apreciação da Diretoria Geral. Sucederam-se duas negociações exitosas, uma delas quanto a aprovação do organograma, atribuições dos níveis hierárquicos e perfis, a outra sobre a quantidade de gerentes de área.

No decorrer deste projeto, os enfermeiros participantes do grupo de estruturação admitiram não ser possível assumir novas responsabilidades sem uma revisão salarial. 0 grupo realizou estudo no mercado local e regional resultando numa proposta salarial que posteriormente foi anexada ao projeto. Entretanto, não houve avanço na negociação salarial por indefinição da administração, ocasionando estagnação das demais propostas do projeto.

Após três meses a Administração contratou uma consultoria externa com a finalidade de organizar a prestação de serviço aos usuários do plano de saúde próprio da instituição, recentemente lançado. Após diagnóstico situacional, esta consultoria identificou a necessidade de que previamente deveria trabalhar na organização dos departamentos. Dessa forma, em dois meses foi construído e implantado o regimento do Serviço de Enfermagem.

Este posicionamento por parte da Administração e enfermeiros/docentes motivou o presente estudo sobre a influência do poder e da cultura organizacional na proposta da estrutura organizacional do Serviço de Enfermagem de um hospital-ensino.

\section{RESULTADOS E DISCUSSÃO}

A análise do caso foi realizada sob dois aspectos: 1 . Conflito - interesses operacionais $x$ estratégicos e; 2 . Processo de negociação - tipo e estilo.

\section{Conflito}

A padronização dos procedimentos de enfermagem era importante tanto para a parte solicitante, ou seja, a administração do hospital que apontava tal necessidade, quan- to para a solicitada, isto é, a equipe de enfermagem para organizar o trabalho deste Serviço. Apesar de não haver a descrição dos procedimentos, estes estavam interiorizados nos trabalhadores de enfermagem da instituição em estudo.

Contudo, os interesses eram divergentes, uma vez que havia intencionalidade econômica por parte da administração, devido à alta demanda por procedimentos de enfermagem no ambiente hospitalar. $\mathrm{O}$ alto consumo de recursos nesses procedimentos gera oportunidades de ações administrativas para a redução de custos, otimização de recursos dos procedimentos, bem como ações educativas de âmbito econômico. Embora a intencionalidade econômica não tenha sido verbalizada, entendia-se ser este o objetivo dos membros que representavam os interesses da instituição. Assim, seus interesses estavam limitados ao âmbito operacional da eficiência dos procedimentos de enfermagem, o que levavam-Ihes a concluir que para a organização, o valor da enfermagem estava no fazer reflexo de sua cultura, tela de fundo, internalizada por todos. Aliada a essa questão, estava a solicitação da instituição na capacitação dos enfermeiros no gerenciamento da rotina do dia-a-dia. Este fato reforçava os interesses e a cultura organizacional à medida que esta capacitação direcionava o desempenho dos profissionais para o nível operacional. Por outro lado, o enfermeiro ao realizá-lo, sem perceber, reproduzia e reforçava o mesmo modelo. Relata-se na literatura que normalmente, as capacitações são elaboradas de forma alienada, sem perceber que subjacente às suas decisões, está a conformação de comportamentos desejados por outros níveis decisórios ${ }^{(16)}$.

Por outro lado, o interesse dos enfermeiros que representavam o Serviço de Enfermagem estava relacionado à organização do trabalho, ou seja, divisão de tarefas (entre enfermeiros, enfermeiros e nível técnico, enfermeiro e demais profissionais da saúde); às responsabilidades, disputa por poder e controle. Esses enfermeiros vislumbraram essa oportunidade para trabalhar no nível estratégico, elaborando uma proposta de descentralização do poder da chefia, incluindo novas gerências; isto denotava a necessidade de ampliar a área de influência e controle, ou seja, ampliar o poder enquanto grupo. Dessa forma, passou a existir um conflito de caráter relacional entre representantes da organização (administração) e grupo de enfermeiros representando o Serviço de Enfermagem.

Os conflitos são manifestações das configurações do poder na organização, portanto, devem ser compreendidos nas suas formas declaradas ou silenciosas. Ainda, a compreensão de como os conflitos são tratados ou negados desvela as reais relações de poder existentes na organização ${ }^{(17)}$.

A inexistência de descrição das atribuições e perfis para cada nível hierárquico traz dificuldades para o gerenciamento e ações dos enfermeiros, gerando muitas vezes conflitos e ambigüidades nas decisões, bem como comprometendo a qualidade da assistência dispensada ao cliente. Isto leva a uma reflexão de que se estas questões não 
forem trabalhadas, a padronização dos procedimentos ficaria somente em nível de registros (atenderia aos interesses explícitos da administração) sem aplicação na prática assistencial (não atenderia aos interesses implícitos). Estudos realizados, anteriormente, nesse mesmo hospital de ensino, na década de noventa, já evidenciavam a falta de clareza das atribuições para cada cargo e funções exercidas pelos enfermeiros. Consequentemente dificultava o desenvolvimento das ações destes profissionais ${ }^{(18)}$ como também a possível correlação entre a não definição do papel do enfermeiro e a falta de valorização do serviço de enfermagem ${ }^{(19)}$. Percebe-se que mesmo após a identificação do problema, ele permaneceu sem resolução, revelando uma cultura de indefinição.

Observa-se no cotidiano muitas situações geradoras de conflito entre elas as relacionadas às escalas diárias, mensais e de férias, principalmente associadas aos feriados, finais-de-semana prolongados e aos meses declarados de férias. Estudo realizado ${ }^{(20)}$ em clínica médica, cirúrgica e pronto-socorro, demonstrou que os conflitos são decorrentes da falta de clareza da missão, visão e valores da instituição, da depreciação do ambiente físico de trabalho, de formas distintas de contratações, da má organização do serviço de enfermagem, de relacionamentos pessoais e grupais conflituosos e, ainda, da comunicação e das dimensões da liderança pouco desenvolvidas. Outro estudo em Unidade de Clínica Cirúrgica e Centro de Material e Esterilização identificou a falta de material e normas descritas como causas freqüentes de conflitos e atritos ${ }^{(21)}$. Ainda, na literatura são relatados falta de definição clara de papéis, invasão do espaço por outros profissionais, alta rotatividade, quantitativo insuficiente do quadro de pessoal, problemas externos ao trabalho, sentimentos de desvalorização, dificuldades com pacientes e familiares, falta de confiança, clima organizacional e diferenças de idade ${ }^{(22)}$.

O enfermeiro gasta $20 \%$ do tempo lidando com conflitos e apresenta atitude passiva na sua resolução, atitude esta que não vai ao encontro dos propósitos da gestão contemporânea em enfermagem ${ }^{(23)}$.

Para administrar o conflito ${ }^{(24)}$, o enfermeiro e sua equipe devem: 1 - identificar o problema; 2 - analisar sua causa; 3 - empregar esforços para eliminá-lo e; 4 - prevenir futuras ocorrências.

Em relação à resolução dos conflitos, estudo(20) aponta que a postura do enfermeiro é fundamentada em valores ou em experiências anteriores, atenuando o conflito, pois o mesmo volta a se repetir. Às vezes o conflito é ignorado ou nem se fica sabendo dos fatos e, em casos mais graves, utiliza-se o sistema de punição institucional. Em outra investigação ${ }^{(25)}$, observou-se inadequação no manejo do conflito interpessoal com ruptura da comunica- ção entre os elementos do grupo, ambiente menos produtivo, entropia e clima organizacional desfavorável, causando sofrimento pessoal e tensão coletiva. Muitas vezes os gerentes de enfermagem em situações de conflito não desistem da negociação, estabelecem confronto, demonstrando inabilidade em lidar com tais situações ${ }^{(26)}$.

As táticas para lidar com os conflitos ${ }^{(27)}$ sugerem comunicação assertiva, negociação, acomodação, compromisso, competição e colaboração. A forma mais comum de resolver um conflito é por meio do processo de negociação. Habilidades de negociação bem sucedidas resolvem conflitos e encorajam a colaboração, gerando um ambiente positivo de trabalho ${ }^{(22)}$.

\section{Negociação}

O poder nas organizações de saúde é compartilhado por vários núcleos profissionais, o que reforça a necessidade de aprimoramento da comunicação e da capacidade de negociação dos gerentes. Assim, a negociação é do tipo cooperativo quando os interesses são distintos, mas o objetivo comum, levando os profissionais a uma disputa positiva. Contudo, quando os interesses são opostos, a negociação é conflitiva com resultado nulo. $O$ terceiro tipo de negociação é misto quando esta é baseada em interesses opostos combinados, com resultado também mesclado(28).

Na situação vivenciada, na primeira etapa o grupo seguiu a arquitetura do processo de negociação com a elaboração da proposta do desenho da estrutura organizacional do SE. Na mesa de negociação foi feita a apresentação para a administração descrevendo as atribuições e perfis requeridos pelos níveis hierárquicos, fechando o acordo com a aprovação da proposta. Assim, entendemos que a negociação foi do tipo cooperativo apresentando interesses distintos, mas o objetivo comum, levando a um resultado positivo.

Contudo, gerou outra negociação, pois a Administração afirmou que não poderia atender a quantidade de gerentes de área, solicitando compromisso do grupo em rever a redução da quantidade desenhada na proposta. Para tanto, a análise do quadro de pessoal e a redistribuição dos enfermeiros tornou-se imprescindível para a viabilidade da proposta. Várias foram as dificuldades, principalmente em relação ao aspecto legal, que exigiam mudanças nos contratos e salários, uma vez que a jornada de trabalho diferia entre o grupo de enfermeiros.

Na segunda etapa o grupo voltou à mesa de negociação com a administração para a questão quantitativa do gerente de área reduzindo a proposta inicial, entendendo a concessão como estratégia importante naquele momento e também como demonstração de flexibilidade, fechando acordo em cinco enfermeiros. Conclui-se que a negoci-

$\begin{array}{rr}\begin{array}{r}\text { Rev Esc Enferm USP } \\ 2008 ; 42(3): 569-77 .\end{array} & \text { Estrutura organizacional do serviço de enfermagem: } \\ \text { www.ee.usp.br/reeusp/ } & \text { reflexóes sobre a influência do poder e da cultura... } \\ \text { Jericó MC, Peres AM, Kurcgant } P\end{array}$


ação foi do tipo misto com interesses opostos, porém combinados, onde ambas as partes fizeram concessões.

A terceira etapa foi guiada pela necessidade de reconhecimento financeiro em assumir novas responsabilidades. Quando a proposta salarial foi apresentada à mesa de negociação, a administração argumentou que precisaria fazer análise da questão e que nova data seria marcada para decisão. Esta etapa resultou em adiamento da decisão.

A quarta etapa foi marcada por questionamentos do grupo junto à administração sobre a nova data anteriormente combinada. Contudo, o silêncio por parte da administração em rever a questão salarial, demonstrou a falta de interesse em negociar a proposta. Entendeu-se uma retirada implícita da mesa de negociação, estacionou-se o processo com resultado nulo evidenciado pelo tipo de negociação implícita conflitiva.

Os espaços formais e informais de negociação servem para dar transparência aos fatos, disputar interesses e negociar poder, constituindo-se em momentos tensos pontuados de conflitos que se finalizam com consensos mínimos ou com rachaduras do grupo em facções. É possível dizer que sempre há recomposição das forças internas, diante de situações de conflito ${ }^{(29)}$.

Saber lidar com diferentes estilos do interlocutor numa negociação pode representar um diferencial na prática profissional. Os negociadores podem ser agrupados em quatro estilos básicos ${ }^{(30)}$, segundo seu comportamento dominador e condescendente, formal e informal em: catalizador, controlador, apoiador e analítico.

Assim, o grupo de enfermeiros demonstrou estilo catalizador identificado por meio da inovação, criatividade e mudança evidenciada pela proposta (gerente de área, visibilidade, descentralização e fortalecimento do poder). Estudo $^{(31)}$ mostra predomínio do estilo catalizador entre estudantes de enfermagem. Por outro lado, a boa idéia foi perdida por inabilidade no processo de negociação, uma vez que o acordo não é o término da negociação e sim seu cumprimento, ou seja, as conquistas negociadas deveriam ter sido implementadas. Estudo sobre a condução do processo de negociação por parte de gerentes de enfermagem $^{(26)}$ mostra que características institucionais interferem no processo de negociação e, que gerentes de instituições de caráter privado adotam atitudes mais diplomáticas quando comparados aos de instituições públicas. Têm preocupação em conciliar interesses divergentes, coletam informações complementares e avaliam o alcance dos objetivos.

Os resultados de uma negociação podem ser explicados pelas características dos negociadores, a situação em que é realizada e pelo processo da negociação em si, sendo essas três categorias de variáveis influenciadas pela cultura ${ }^{(32)}$.

A evolução do processo de negociação remete à reflexão de que após a primeira e segunda etapa da negocia- ção, a situação pedia a consolidação da ampliação de poder, favorável à enfermagem e aceita por parte da administração. Quando o grupo passou a tratar da questão salarial, ficou evidente o desvio do objetivo inicial dos enfermeiros/docentes, que era o de implementar, formalmente, a estrutura organizacional do Serviço de Enfermagem. Os resultados refletem a cultura de que a aspiração pelo poder na enfermagem ainda não se constitui em prioridade. Estes achados vêm de encontro a um estudo realizado sobre a cultura da enfermagem ${ }^{(6)}$ em que foi identificada a necessidade de poder por apenas $7 \%$ dos enfermeiros em um hospital de ensino.

O estilo demonstrado pela Administração foi o de controlador, delineado pela busca de resultados, redução de custos, menor receptividade e autoritário, quando solicitou a redução quantitativa dos gerentes de área e em relação à questão salarial. A hegemonia administrativa do poder médico dentro dos hospitais que obedece a uma lógica dominante a do trabalho médico, foi demonstrada com a paralisação do processo de negociação (dando a última palavra o silêncio) e autorização da consultoria externa em implantar o regimento de enfermagem, segundo a prática tradicional vigente. Esse estilo não se importa com as outras pessoas, considera-as apenas como recursos na realização de tarefas e procura atingir as metas sem se importar com os meios ${ }^{(32)}$. Já em 1998, foi investigada as percepções dos gerentes de enfermagem em relação ao estilo gerencial do diretor executivo do hospital em estudo, utilizando o Grid Gerencial. Verificou-se que o mesmo trabalhava voltado para o cumprimento de tarefas, não desviando da rotina fixada, mostrando-se centralizador, impessoal e objetivando a produtividade.

\section{CONSIDERAÇÕES FINAIS}

As reflexões realizadas sobre a proposta da estrutura organizacional do Serviço de Enfermagem da instituição do estudo permitiram algumas considerações para compreender melhor a situação vivida.

O desenrolar dos acontecimentos nesta investigação mostrou que a cultura organizacional veio definindo a indefinição da estrutura organizacional e, também evidenciou o conflito de interesses entre as partes - operacional $x$ estratégica.

O processo de negociação junto à administração geral deu-se em quatro etapas: a primeira foi do tipo cooperativo; a segunda do tipo misto; a terceira foi suspensa e a quarta foi de forma implícita conflitiva.

O ponto crítico que bloqueou a continuidade das negociações foi a solicitação, naquele momento, de revisão salarial. As cobranças dos enfermeiros em relação à data para a quarta etapa na mesa de negociação resultou em silêncio da outra parte, esse resultado nulo ocasionou o esvaziamento dos avanços das negociações anteriores. 
Por outro lado, ficou evidente o desvio do objetivo por parte dos enfermeiros/docentes, que era o de implementar, formalmente, a estrutura organizacional do Serviço de Enfermagem. Isto reforçou a inabilidade de negociação no que diz respeito à consecução de objetivos. A demanda por uma remuneração diferenciada viria a seguir e naturalmente.

A consultoria externa, em curto período de tempo, orientou a construção e implementação do regimento do Serviço de Enfermagem, unidades de internação geral e espe-

\section{REFERÊNCIAS}

1. Mintzberg H, Quinn JB. O conceito de estratégia. In: Mintzberg H, Quinn JB. O processo da estratégia. 4a ed. Porto Alegre: Bookman; 2006. p. 19-32.

2. Marquis BL, Huston CJ. Administração e liderança em enfermagem: teoria e aplicação. 4a ed. Porto Alegre: Artmed; 2005.

3. Chiavenato I. Introdução à teoria geral da administração. 7ạ ed. São Paulo: Campus; 2004.

4. Luck H. A melhoria do desempenho da empresa pela mudança de sua cultura. Rev FAE. 2001; 4(1):3-16.

5. Katz D, Kahn RL. Psicologia social das organizações. São Paulo: Atlas; 1970.

6. Olchowsky A, Chaves EHB. A realização, a afiliação e o poder: em qual destes três fatores está calcada a motivação dos enfermeiros em um hospital de ensino? Rev Gauch Enferm. 1997;18(1):9-16.

7. Zalesnik A, Vries MFRK. O poder e a mente empresarial. Trad. de Regina Chiguetto e Oswaldo Chiguetto. São Paulo: Pioneira; 1981.

8. Foucalt M. Microfísica do poder. 23a ed. Rio de Janeiro: Graal; 2007.

9. Pages M. O poder das organizações: a dominação das multinacionais sobre os indivíduos. São Paulo: Atlas; 1987

10. Segnini L. A liturgia do poder: trabalho e disciplina. São Paulo: EDUC; 1988.

11. Mendes DC. Algumas considerações sobre o perfil do enfermeiro na função gerencial da assistência de enfermagem. Rev Gauch Enferm. 1988;9(2):67-72.

12. Kertesz PM. Gerenciamento no serviço de enfermagem. Mundo Saúde. 1984;4(1):160-3.

13. Campos VF. TQC: Controle da Qualidade Total (no estilo japonês). 8a ed. Belo Horizonte: Fundação Christiano Ottoni, Escola de Engenharia da UFMG; 2000.

14. Garapinheiro G. Saberes e poderes no hospital: uma sociologia dos serviços hospitalares. 3a ed. Lisboa: Afrontamento; 1998. cializadas nos moldes como se davam na prática, reforçando a cultura e poder instituídos.

Conclui-se que a força da cultura e poder nas organizações de saúde determinam as relações de trabalho, e a hegemonia médica administrativa nutre uma dinâmica tradicional, autoritariamente implícita. Nesta perspectiva é indispensável ao enfermeiro gestor, desenvolver habilidades para gerenciar conflitos e negociação, a fim de criar uma nova cultura.
15. Fávero N. O gerenciamento do enfermeiro na assistência ao paciente hospitalizado [tese livre- docência]. Ribeirão Preto: Escola de Enfermagem de Ribeirão Preto, Universidade de São Paulo; 1996.

16. Kurcgant $P$, Massarollo MCKB. Cultura e poder nas organizações de saúde. In: Kurcgant $P$, coordenadora. Gerenciamento em enfermagem. Rio de Janeiro: Guanabara Koogan; 2005. p. 26-36.

17. Cecílio LCO, Moreira ME. Disputa de interesses, mecanismos de controle e conflitos: a trama do poder nas organizações de saúde. Rev Adm Publ. 2002;36(4):587-608.

18. Ittavo J. Inserção de enfermeiros recém-graduados admitidos em área hospitalar: um programa de educação conscientizadora [dissertação]. Ribeirão Preto: Escola de Enfermagem de Ribeirão Preto, Universidade de São Paulo; 1997.

19. Perroca MG, Soler ZASG. O desempenho profissional de enfermeiras de um hospital de ensino: influência da cultura organizacional. Acta Paul Enferm. 1998; 11(3):16-23.

20. Agostini R. O conflito como fenômeno organizacional: identificação e abordagem na equipe de enfermagem de um hospital público [dissertação]. Ribeirão Preto: Escola de Enfermagem de Ribeirão Preto, Universidade de São Paulo; 2005

21. Moura JFP. Relacionamento: a fronteira entre os auxiliares de enfermagem da Unidade Central de Material Esterilizado e os das Unidades de Internação Cirúrgicas [dissertação]. Rio de Janeiro: Universidade do Estado do Rio de Janeiro; 2000.

22. Marx LC. Competências da enfermagem: sedimentadas no Sistema Primary Nursing. Rio de Janeiro: EPUB; 2006.

23. Valentine PE. A gender perspective on conflict management strategies of nurses. J Nurs Scholarsh. 2001; 33(1):69-74.

24. Smith $\mathrm{MH}$. Grievance procedures resolve conflict. Nurs Manage. 2002;33(4):13, 56.

25. Falk ML. A competência gerencial nos conflitos interpessoais [dissertação]. Porto Alegre: Universidade Federal do Rio Grande do Sul; 2000. 
26. Jericó MC, Perroca MG. Negociar: uma habilidade gerencial imprescindível. Nursing (São Paulo). 2001; $4(32): 14-7$.

27. Brandt MA. How to make conflict work for you. Nurs Manage. 2001;32(11):32-5.

28. Matus C. Política, planejamento e governo. Brasília: Instituto de Pesquisa Econômica Aplicada; 1993.

29. Ferraz CA. Ensaio sobre reforma político-administrativa: análise sociológica da transição de modelos de gestão [tese livre-docência]. Ribeirão Preto: Escola de Enfermagem de Ribeirão Preto, Universidade de São Paulo; 2002.

30. Junqueira LAC. Negociação: tecnologia e comportamento. Rio de Janeiro: COP; 1998.
31. Pereira RM, Jericó MC, Perroca MG. Negociação: estilo dos acadêmicos do último ano do curso de graduação em enfermagem. In: Anais do 9o Encontro Científico da FAMERP; 2003; São José do Rio Preto, BR. São José do Rio Preto: Faculdade de Medicina de São José do Rio Preto; 2003. p. 64.

32. Godinho WB, Macioski JMK. Estilos de negociação: a maneira pessoal de realizar negócios internacionais. Ciênc Opinião. 2005;2(1/2):143-65.

33. Beccaria LM. O estilo gerencial do diretor executivo de um hospital de ensino: percepções e expectativas de gerentes de enfermagem [dissertação]. Ribeirão Preto: Escola de Enfermagem de Ribeirão Preto, Universidade de São Paulo; 1998. 